\title{
CONSÓRCIO SORGO-SOJA. I. PRODUÇÃO DE FORRAGEM DE CULTIVARES DE SOJA E HÍBRIDOS DE SORGO, CONSORCIADAS NA LINHA, EM DOIS SISTEMAS DE CORTE ${ }^{1}$
}

\author{
SORGHUM-SOYBEAN INTERCROPPING. I. PRODUCTION OF FORAGE OF SORGHUM \\ HYBRIDS AND SOYBEAN CULTIVARS, INTERCROPPED ON THE LINE, \\ IN TWO CUTTING SYSTEMS
}

\author{
Alessandro Guerra da Silva ${ }^{2}$ Pedro Milanez de Rezende ${ }^{3}$ Luiz Antônio de Bastos Andrade ${ }^{4}$ \\ Antônio Ricardo Evangelista ${ }^{5}$
}

\section{RESUMO}

Visando selecionar cultivares de sorgo e soja de melhor rendimento forrageiro no consórcio, foi conduzido, em 1996/97, um ensaio no Departamento de Agricultura no Campus da Universidade Federal de Lavras, em Lavras, MG, em um Latossolo Roxo distrófico. $O$ delineamento experimental utilizado foi o de blocos casualizados em esquema fatorial $2 \times 4 \times 4+4$ com três repetições, sendo constituído por dois sistemas de corte (um único corte, rente ao solo, de ambas as culturas no estádio $R_{5} d a$ soja e um sistema de dois cortes: o primeiro feito aos 60 dias após a emergência a $30 \mathrm{~cm}$ do solo e o segundo, após a rebrota das plantas, rente ao solo, na mesma época do corte do primeiro sistema), quatro cultivares de soja (CAC-1, Doko RC, UFV-16 e $U F V$-17) e quatro híbridos de sorgo forrageiro ( $A G$ 2002, $A G$ 2006, BR 601 e CMSXS 756), e mais os quatros cultivares de sorgo em monocultivo. Os diferentes sistemas de corte alteraram significativamente os rendimentos de massa verde, matéria seca e proteína bruta total. A utilização do consórcio proporcionou maior rendimento de proteína bruta total, quando comparado ao monocultivo, sendo que as combinações UFV-16 $x$ AG 2002 e CAC-1 x AG 2006 foram as de maior destaque para o sistema de um corte. No sistema de dois cortes, sobressaíram-se Doko RC x AG 2006 e BR 601 e Doko RC x BR 601. Em condição de monocultivo e consórcio, o híbrido de sorgo que proporcionou maior rendimento de massa verde, matéria seca e proteína bruta total foi o AG 2002.

Palavras-chave: rebrota, monocultivo, matéria seca.

SUMMARY

Aiming to select sorghum and soybean cultivars of best forage yield in the intercropping on the line, a trial was conducted in 1996/1997, at the Department of Agriculture on the campus of the Universidade Federal de Lavras, in Lavras, MG, Brazil, on a Distrophic Red Dusky Latosol. The experimental design utilized was that of randomized blocks in factorial scheme $2 \times 4 \times 4+4$ with three replications, being made up of two cutting systems (a single cutting, close-cut to the soil, of both crops at the $R_{5}$ stage of soybean and a two-cutting system: the first done at 60 days after emergence at $30 \mathrm{~cm}$ from the soil and the second after regrowth of the plants, close-cut to the soil at the same time of the cutting of the first system), four soybean cultivars (CAC-1, Doko $R C, U F V-16$ and $U F V-17)$ and four hybrids of forage sorghum (AG 2002, AG 2006, BR 601 and CMSXS 756), and four hibrids of sorghum in monoculture. The one cutting system was superior than the two cutting system in relation of green mass and dry matter. The grude protein was superioty in the two cutting system. Use of the intercropping on the line provided greater yield total crude portein as compared with monoculture, being that the combinations UFV-16 and UFV-17 xAG 2002 and CAC-1 $x$ AG 2006 were the ones which stood out the most to the one-cutting system. In the two-cutting system, Doko RC x AG 2006 and BR 601 and UFV-16 x BR 601 stood out. Under monoculture and intercropping on the line condition, the sorghum hybrid which presented the highest yield of green mass, dry matter and total crude protein was AG 2002.

Key words: regrowth, monoculture, dry matter.

\section{INTRODUÇÃO}

No Brasil, o cultivo de uma ou mais culturas numa mesma área já vem de longos anos, en-

\footnotetext{
${ }^{1}$ Extraído da Dissertação de Mestrado em Fitotecnia, do primeiro autor, realizada na Universidade Federal de Lavras (UFL).

${ }^{2}$ Engenheiro Agrônomo, Pós-graduando do Departamento de Agricultura da UFL, Caixa Postal 37, 37200-000. Lavras, MG.

${ }^{3}$ Engenheiro Agrônomo, Doutor, Professor Titular do Departamento de Agricultura da UFL, (Bolsista do CNPq). Autor para correspondência.

${ }^{4}$ Engenheiro Agrônomo, Doutor, Professor Titular do Departamento de Agricultura da UFL, (Bolsista do CNPq).

${ }^{5}$ Engenheiro Agrônmo, Doutor, Professor Titular do Departamento de Zootecnia da UFL, (Bolsista do CNPq).
}

Recebido para publicação em 04.11.98. Aprovado em 26.04.00 
tretanto, apenas recentemente, os pesquisadores têm demonstrado maior interesse por essa prática. Neste contexto, várias opções se apresentam, com um destaque especial para gramíneas e leguminosas, sendo o sistema milho e soja um dos mais importantes (REZENDE, et al. 1992; CARVALHO, 1993 e REZENDE, 1995).

A crescente procura do milho para alimentação humana e animal tem levado os pesquisadores a procurarem formas alternativas para a alimentação de ruminantes. Dentre as diversas espécies de plantas forrageiras, a cultura do sorgo se apresenta como espécie promissora na elaboração de silagens, pois suas características nutritivas, o cultivo e também o rendimento de forragem são muito semelhantes à cultura do milho. Devido a este fato, essa cultura tem sido estudada como sucedânea a do milho, principalmente, nas regiões semi-áridas, onde a mesma possui melhor rendimento.

Admitindo-se que a demanda forrageira em uma propriedade agrícola permanece constante durante todo o ano, a suplementação no período seco seria a alternativa mais viável para a manutenção da produtividade animal, às vezes nem sempre viável economicamente. A prática da ensilagem é considerada técnica fundamental na conservação de forragens, sendo enriquecida pela adição de suplementos produzidos na própria propriedade, proporcionando maior ganho de peso dos animais com custo mais baixo. Neste contexto, a utilização da soja nos sistemas consorciados proporciona alguns benefícios, justificando sua maior utilização no material ensilado (EVANGELISTA, 1986 e SOOD \& SHARMA, 1992).

Além das vantagens já relatadas anteriormente, as plantas de soja e sorgo têm comprovado poder de rebrota após o corte, podendo fornecer em conjunto mais forragem por unidade de área em consórcio quando comparado ao monocultivo da gramínea. Após os cortes, as plantas irão rebrotar, podendo essa rebrota ser utilizada novamente na forma de forragem ou de grãos, dependendo da necessidade do agricultor, o mesmo se verificando em função das plantas de sorgo.

O objetivo do trabalho foi selecionar cultivares de sorgo e soja, com alta capacidade de rebrota em condição de consórcio, comparados à produção de forragem obtida no monocultivo do sorgo.

\section{MATERIAL E MÉTODOS}

O ensaio foi instalado em Lavras - MG (latitude de $21^{\circ} 14^{\prime} \mathrm{S}$, longitude $45^{\circ} 00 \mathrm{~W}$ e altitude de 900m) em Latossolo Roxo distrófico, de textura argilosa fase cerrado (Tabela 1) no campo experi-
Tabela 1 - Resultados das análises químicas da amostra de solo coletada na profundidade de $0-20 \mathrm{~cm}$ na área experimental, UFLA, Lavras (MG), 1996.

\begin{tabular}{lcc}
\hline & Valores & Classificação** \\
\hline & & \\
pHeterminações & 5,1 & Médio \\
$\mathrm{P}\left(\mathrm{mg} / \mathrm{dm}^{3}\right)$ & 11 & Alto \\
$\mathrm{K}\left(\mathrm{mg} / \mathrm{dm}^{3}\right)$ & 58 & Médio \\
$\mathrm{Ca}\left(\mathrm{cmolc} / \mathrm{dm}^{3}\right)$ & 2,8 & Médio \\
$\mathrm{Mg}\left(\mathrm{cmolc}^{3} \mathrm{dm}^{3}\right)$ & 0,9 & Médio \\
$\mathrm{Al}\left(\mathrm{cmolc} / \mathrm{dm}^{3}\right)$ & 0,2 & Baixo \\
$\mathrm{H}+\mathrm{Al}\left(\mathrm{cmolc} / \mathrm{dm}^{3}\right)$ & 5,0 & Médio \\
$\mathrm{S}\left(\mathrm{cmolc} / \mathrm{dm}^{3}\right)$ & 3,8 & Médio \\
$\mathrm{t}\left(\mathrm{cmolc} / \mathrm{dm}^{3}\right)$ & 4,0 & Médio \\
$\mathrm{T}\left(\mathrm{cmolc} / \mathrm{dm}^{3}\right)$ & 8,8 & Médio \\
$\mathrm{m}(\%)$ & 5 & Baixo \\
$\mathrm{v}(\%)$ & 43 & Baixo \\
MAT. ORG. $\left(\mathrm{dag} / \mathrm{dm}^{3}\right)$ & 3,1 & Alto \\
AREIA $(\%)$ & 30 & \\
LIMO $(\%)$ & 26 & \\
ARGILA $(\%)$ & 44 & \\
& & \\
\hline
\end{tabular}

*Análises realizadas no Instituto de Química "John H. Wheelock" do Departamento de Ciências do Solo da Universidade Federal de Lavras, Lavras (MG).

**Interpretação dos resultados de acordo com a Comissão de Fertilidade do Solo do Estado de Minas Gerais (1989).

mental do Departamento de Agricultura da Universidade Federal de Lavras - UFLA, ano agrícola 1996/97.

A semeadura foi realizada em 22/10/96, utilizando-se quatro cultivares de soja (CAC-1, Doko RC, UFV-16 e UFV-17) com ótimo desempenho na região, consorciadas na linha com quatro híbridos de sorgo forrageiro (AG 2002 e AG 2006 híbridos mais plantados na região e BR 601 e CMSXS 756 lançamentos recentes). Esses materiais foram avaliados em todas as combinações possíveis em dois sistemas de corte, sendo as épocas de corte determinadas em função da cultura da soja. No primeiro sistema, as plantas de ambas espécies foram cortadas uma única vez rente ao solo, quando as plantas de soja atingiram o estádio $\mathrm{R}_{5}$ (início da formação da semente) de acordo com FEHR \& CAVINESS (1977). No segundo sistema, ambas as culturas foram cortadas duas vezes, sendo o primeiro corte realizado à altura de $30 \mathrm{~cm}$ do colo das plantas aos 60 dias após emergência e o segundo corte, após a rebrota, rente ao solo, na mesma época do corte do primeiro sistema (estádio $\mathrm{R}_{5}$ ).

$\mathrm{O}$ delineamento experimental empregado foi o de blocos casualizados com três repetições em esquema fatorial $2 \times 4 \times 4+4$ constituído pelos dois sistemas de corte, quatro cultivares de soja e sorgo. Adicionalmente, foi conduzido outro ensaio contíguo em blocos casualizados com três repetições para 
o monocultivo de sorgo, sendo que, neste caso, os cortes foram realizados uma única vez, rente ao solo, no estádio de grãos farináceos.

Tanto no monocultivo como no consórcio, as parcelas de sorgo foram constituídas por três linhas espaçadas de $0,8 \mathrm{~m}$ com 5,0m de comprimento, sendo considerada como área útil apenas a fileira central $\left(4,0 \mathrm{~m}^{2}\right)$. Para a cultura da soja, foi utilizado o sistema de consórcio na linha do sorgo, utilizando também uma linha como área útil. O desbaste foi realizado aos 25 dias após a emergência das plântulas, procurando-se manter 12 plantas por metro linear para a cultura do sorgo e soja (150.000 plantas/ha) no consórcio e também no monocultivo de sorgo.

Para o sorgo, em condição de consórcio e monocultivo, a calagem e adubação seguiram as recomendações feitas pela COMISSÃO DE FERTILIDADE DO SOLO DO ESTADO DE MINAS GERIAS (1989), utilizando-se o correspondente a $20 \mathrm{~kg}$ de $\mathrm{N}, 120 \mathrm{~kg}$ de $\mathrm{P}_{2} \mathrm{O}_{5}$ e $120 \mathrm{~kg}$ de $\mathrm{K}_{2} \mathrm{O} /$ ha. Aos 30 e 45 dias após emergência das plântulas de sorgo, aplicaram-se $60 \mathrm{~kg}$ de N/ha em cobertura. No caso do consórcio, a cultura da soja não foi adubada, utilizando-se apenas a adubação recomendada para o sorgo forrageiro nas mesmas dosagens do monocultivo de sorgo.

Antes da semeadura, foi feita a inoculação das sementes de soja com Bradyrhizobium japonicum, utilizando o inoculante turfoso Nitral na proporção de $200 \mathrm{~g}$ de inoculante para $50 \mathrm{~kg}$ de sementes. As parcelas foram mantidas livres de invasoras sendo realizadas duas capinas manuais.

$$
\text { O corte das }
$$

plantas de soja e sorgo foi realizado manualmente com o auxílio de roçadeira costal motorizada nas épocas já relatadas anteriormente. Os materiais foram pesados, separando-se o sorgo da soja, sendo analisado o rendimento de massa verde $(\mathrm{kg} / \mathrm{ha})$, matéria seca (determinado a partir de amostra de $200 \mathrm{~g}$ de massa verde em estufa a $65^{\circ} \mathrm{C}$ até peso constante e convertido em $\mathrm{kg} / \mathrm{ha}$ ) e de proteína bruta determinada na mesma amostra usada na matéria seca, utilizando metodologia descrita por MALAVOLTA $\boldsymbol{e t}$

**Significativo $1 \%$; * Significativo $5 \%$. al. (1989) e transformando, posteriormente, os dados para $\mathrm{kg} / \mathrm{ha}$.

As análises estatísticas foram realizadas para as características citadas anteriormente, utilizando-se o somatório das duas culturas (sorgo + soja). Para diferenciação das médias obtidas nos fatores de variação significativos sorgo, corte $\mathrm{x}$ sorgo e entre monocultivo, utilizou-se o teste de Duncan 5\%, e para o corte e consórcio versus monocultivo, teste F 5\%. Foi ainda realizada comparação das médias obtidas no consórcio com a utilização de um e dois cortes com o monocultivo do sorgo, utilizando-se o teste "t" de contraste.

\section{RESULTADOS E DISCUSSÃO}

\section{Rendimento de Massa Verde e Matéria Seca Total}

De acordo com a análise de variância, para massa verde total, verificou-se efeito significativo para os sistemas de corte, híbridos de sorgo, interação corte $\mathrm{x}$ sorgo, contraste consórcio versus monocultivo. No caso da matéria seca, ocorreu efeito significativo de todas variáveis citadas anteriormente, a0crescido do monocultivo (Tabela 2).

Levando-se em conta a média dos dois sistemas de corte para o rendimento de massa verde total (Tabela 3), verifica-se um acréscimo de 9,98\% (3.305 kg/ha) a favor do sistema de um corte, o mesmo se verificando em relação à matéria seca total (Tabela 4), sendo esse valor mais elevado

Tabela 2 - Resumo da análise de variância combinada das características rendimento de massa verde, matéria seca e proteína bruta de sorgo + soja em relação ao monocultivo de sorgo obtidas no ensaio de avaliação de cultivares de sorgo e soja em consórcio e monocultivo visando à produção de forragem, UFLA Lavras (MG),1996/97.

\begin{tabular}{|c|c|c|c|c|}
\hline \multirow[b]{2}{*}{ F.V. } & \multirow[b]{2}{*}{ G.L. } & \multicolumn{3}{|c|}{ QUADRADOS MÉDIOS } \\
\hline & & MASSA VERDE & MATÉRIA SECA & PROTEÍNA BRUTA \\
\hline BLOCOS & 2 & $17.507975,26$ & $1.489991,29$ & $78.214,76$ \\
\hline ENTRE CONSÓRCIO & 31 & $435.554 .052,20 * *$ & $40.893 .868,89 * *$ & $139.864,38 * *$ \\
\hline CORTE & 1 & $262.103 .027,34 *$ & $301.996 .437,34 * *$ & $517.362,58 * *$ \\
\hline SOJA & 3 & $7.821 .777,34$ & $1.052 .315,12$ & $87.900,79$ \\
\hline SORGO & 3 & 3.782.322.211,37** & $256.969 .184,07 * *$ & $709.696,97 * *$ \\
\hline SOJA x SORGO & 9 & $50.669 .144,24$ & $1.588 .794,41$ & $31.741,21$ \\
\hline CORTE x SOJA & 3 & $26.380 .805,12$ & $671.043,16$ & $97.085,96$ \\
\hline CORTE X SORGO & 3 & $197.171 .169,70 *$ & $46.414 .338,93 * *$ & $79.356,90$ \\
\hline CORTE x SOJA x SORGO & 9 & $82.551 .378,04$ & $4.010 .411,64$ & $67.848,93$ \\
\hline ENTRE MONOCULTIVO & 3 & $1.304 .435 .329,86^{* *} *$ & $116.552 .966,63 * *$ & $363.065,04 * *$ \\
\hline CONSORCIO. vs MONOCULT. & 1 & $70.826 .790,00$ & $22.248 .579,60 * *$ & $1.939 .667,09 * *$ \\
\hline ERRO MÉDIO & 68 & $64.148 .471,00$ & $3.692 .866,24$ & $44.641,77$ \\
\hline $\mathrm{CV}(\%)$ & & 23,22 & 18,28 & 19,67 \\
\hline
\end{tabular}

Ciência Rural, v. 30, n. 6, 2000. 
Tabela 3 - Resultados médios de massa verde de sorgo e soja $(\mathrm{kg} / \mathrm{ha})$ obtidos no ensaio de avaliação de cultivares de sorgo e soja em consórcio e monocultivo visando à produção de forragem, UFLA Lavras (MG),1996/97.

\section{TRATAMENTO}

SIST. DE UM CORTE SIST. DE DOIS CORTES MÉDIA

\begin{tabular}{|c|c|c|c|c|c|c|}
\hline CAC-1 x AG 2002 & $49.417^{\mathrm{NS}}$ & & $47.959^{\mathrm{NS}}$ & & & 48.688 \\
\hline CAC-1 x AG 2006 & $39.458^{\mathrm{NS}}$ & & $33.125^{\mathrm{NS}}$ & & & 36.292 \\
\hline CAC-1 x BR 601 & $36.958^{\mathrm{NS}}$ & & $31.000^{\mathrm{NS}}$ & & & 33.979 \\
\hline CAC-1 x CMSXS 756 & $17.500^{\mathrm{NS}}$ & & $16.250^{\mathrm{NS}}$ & & & 1.6875 \\
\hline Doko RC x AG 2002 & $50.875^{\mathrm{NS}}$ & & $42.750 *$ & & & 46.813 \\
\hline Doko RC x AG 2006 & $38.333^{\mathrm{NS}}$ & & $35.666^{\mathrm{NS}}$ & & & 37.000 \\
\hline Doko RC x BR 601 & $33.541^{\mathrm{NS}}$ & & $38.958^{\mathrm{NS}}$ & & & 36.250 \\
\hline Doko RC x CMSXS 756 & $17.875^{*}$ & & $22.333 *$ & & & 20.104 \\
\hline UFV-16 x AG 2002 & $55.583^{\mathrm{NS}}$ & & $40.167 *$ & & & 47.875 \\
\hline UFV-16 x AG 2006 & $36.750^{\mathrm{NS}}$ & & $31.583^{\mathrm{NS}}$ & & & 34.167 \\
\hline UFV-16 x BR 601 & $41.667^{\mathrm{NS}}$ & & $44.292^{\mathrm{NS}}$ & & & 42.980 \\
\hline UFV-16 x CMSXS 756 & $16.667^{\mathrm{NS}}$ & & $15.375^{\mathrm{NS}}$ & & & 16.021 \\
\hline UFV-17 x AG 2002 & $56.250^{\mathrm{NS}}$ & & $33.750 *$ & & & 45.000 \\
\hline UFV-17 x AG 2006 & $34.584^{\mathrm{NS}}$ & & $45.209 *$ & & & 39.897 \\
\hline UFV-17 x BR 601 & $40.792^{\mathrm{NS}}$ & & $36.083^{\mathrm{NS}}$ & & & 38.438 \\
\hline UFV-17 x CMSXS 756 & $16.583^{\mathrm{NS}}$ & & $15.458^{\mathrm{NS}}$ & & & 16.021 \\
\hline CAC-1 x SORGO & 35.833 & & 32.083 & & & 33.959 \\
\hline Doko RC x SORGO & 35.156 & & 34.927 & & & 35.042 \\
\hline UFV-16 x SORGO & 37.667 & & 32.854 & & & 35.261 \\
\hline UFV-17 x SORGO & 37.052 & & 32.625 & & & 34.839 \\
\hline AG $2002 \times$ SOJA & $53.031 \quad \mathrm{~A}^{2}$ & $a^{1}$ & 41.157 & $\mathrm{~B}$ & a & 47.094 \\
\hline AG $2006 \times$ SOJA & $37.281 \quad \mathrm{~A}$ & $\mathrm{~b}$ & 36.396 & A & $\mathrm{a}$ & 36.839 \\
\hline BR 601 x SOJA & $38.240 \quad \mathrm{~A}$ & $\mathrm{~b}$ & 37.583 & A & $\mathrm{a}$ & 37.912 \\
\hline CMSXS 756 x SOJA & $17.156 \quad \mathrm{~A}$ & $\mathrm{c}$ & 17.354 & A & b & 17.255 \\
\hline MÉDIA & 36.427 & & 33.122 & & & 34.775 \\
\hline
\end{tabular}

\begin{tabular}{lrrrr} 
MÉDIA & 36.427 & 33.122 & 34.775 \\
\hline & & & & \\
MONOCULTIVO & 56.500 & a & & \\
AG 2002 & 31.083 & b & \\
BG 2006 & 35.500 & b & \\
CMSXS 756 & 5.708 & c & \\
\hline MÉDIA & 32.198 & &
\end{tabular}

1. Médias seguidas pela mesma letra minúscula na coluna não diferem entre si pelo teste de Duncan a $5 \%$ de probabilidade.

2. Médias seguidas pela mesma letra maiúscula na linha não diferem entre si pelo teste de Duncan a $5 \%$ de probabilidade.

** Significativo em nível de 1\%; * Significativo em nível de 5\%; ${ }^{\text {NS }}$ Não significativo.

sistema de um corte, este valor foi de $33,28 \%$, representando excelente teor para se fazer silagem de boa qualidade, sendo o principal responsável pelo aumento verificado (Tabelas 3 e 4$)$.

$\mathrm{O}$ rendimento total de massa verde em consórcio, quando comparado ao monocultivo do sorgo, proporcionou um aumento de $8,0 \%(2.577 \mathrm{~kg} / \mathrm{ha})$ em favor do consórcio, o mesmo não se verificando em relação à matéria seca. Neste caso, o monocultivo proporcionou um aumento de 13,94\% $(1.443 \mathrm{~kg} / \mathrm{ha})$ em relação ao consórcio. Os resultados obtidos, para a matéria seca, são perfeitamente admissíveis uma vez que os cortes no sistema consorciado foram realizados em função da soja e, no monocultivo, em função do sorgo, sendo este, realizado no estádio de grãos farináceos, que segundo FARIA (1986) é a época de maior acumulo de matéria seca na cultura. De uma maneira geral, a contribuição do consórcio para massa verde e matéria seca foi considerada pequena. Esse resultado pode ser justificado pelo fato de o sorgo consorciado ter recebido a mesma adubação do monocultivo e, nessa situação, a soja poderia exercer certa competição com a gramínea na busca de nutrientes. Dadas as explicações acima, é de se esperar que algumas combinações consorciadas apresentassem rendimentos superiores aos respectivos híbridos em monocultivo. Observando-se a tabela 3, verifica-se para massa verde total, apesar de não significativo (teste ' $\mathrm{t}$ '), que todas combi-

$41,35 \% \quad(3.547 \mathrm{~kg} / \mathrm{ha})$. Esse aumento, quando comparado com o rendimento de massa verde total foi maior porque no sistema de dois cortes as culturas de soja e sorgo possuíam um alto grau de umidade em sua forragem, principalmente no segundo corte deste sistema. Isso se deve ao fato de ter levado em consideração no momento dos cortes, o estágio em que a soja se encontrava $\left(\mathrm{R}_{5}\right)$ sendo que os híbridos de sorgo, a exceção do CMSXS 756, encontravam-se no início da fase de grãos leitosos. Em conseqüência, o valor médio de matéria seca observado neste sistema foi $25,90 \%$, ao passo que no nações com o híbrido AG 2002, independente do sistema de corte empregado, apresentaram rendimentos inferiores ao monocultivo $(5.6500 \mathrm{~kg} / \mathrm{ha})$. Já no caso do AG 2006 e BR 601, verifica-se o contrário, ou seja, todas combinações consorciadas foram superiores, embora não significativas ao rendimento observado com os híbridos em monocultivo, exceto as combinações Doko RC e CAC-1 x BR 601 que no sistema de um e dois cortes apresentaram rendimentos de $(33.541$ e $31.000 \mathrm{~kg} / \mathrm{ha})$ inferiores ao obtido no monocultivo $35.500 \mathrm{~kg} / \mathrm{ha}$. Resultado semelhante foi observado com o híbrido CMSXS 756. Nesse caso, como o híbrido apresentou pior desem- 
Tabela 4 - Resultados médios de matéria seca de sorgo e soja ( $\mathrm{kg} / \mathrm{ha}$ ) obtidos no ensaio de avaliação de cultivares de sorgo e soja em consórcio e monocultivo visando à produção de forragem, UFLA Lavras (MG),1996/97.

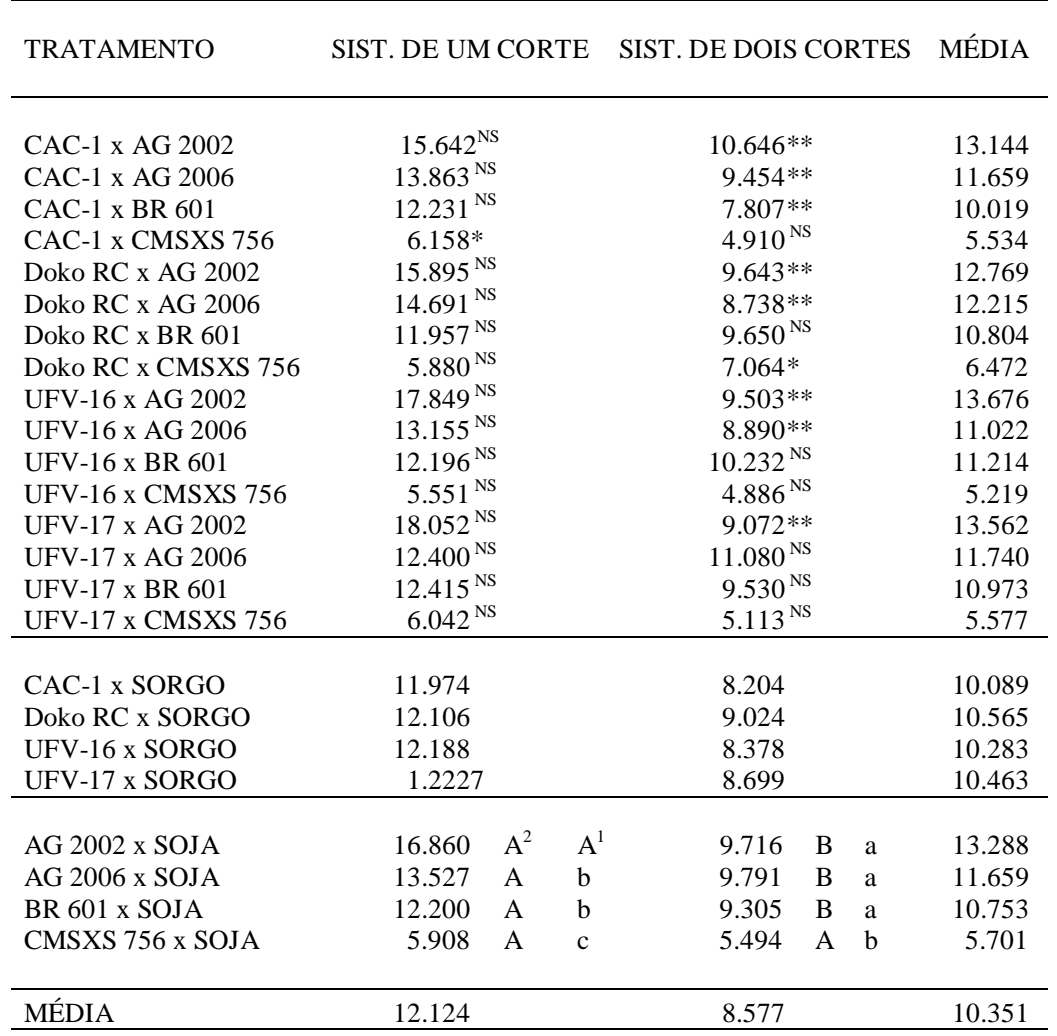

\begin{tabular}{lrl} 
MONOCULTIVO & & \\
AG 2002 & 17.943 & a \\
AG 2006 & 13.871 & b \\
BR 601 & 12.186 & b \\
CMSXS 756 & 3.176 & c \\
\hline & & \\
MÉDIA & 11.794 &
\end{tabular}

1. Médias seguidas pela mesma letra minúscula na coluna não diferem entre si pelo teste de Duncan a $5 \%$ de probabilidade.

2. Médias seguidas pela mesma letra maiúscula na linha não diferem entre si pelo teste de Duncan a $5 \%$ de probabilidade.

** Significativo em nível de $1 \%$; * Significativo em nível de $5 \%$; ${ }^{\text {NS }}$ Não significativo.

CMSXS 756, os resultados foram semelhantes aos observados com a massa verde, tendo sido observados valores de combinações consorciadas superiores ao monocultivo, independente do sistema de corte utilizado e, em alguns casos, até significativas como ocorreu com as combinações de soja CAC-1 e Doko RC no sistema de um corte e dois cortes respectivamente. Os resultados de matéria seca total obtidos neste ensaio são menores que os encontrados por OLIVEIRA (1989) que obteve rendimentos de $14,8 \mathrm{t} / \mathrm{ha}$ com o sorgo BR 601 a $18,6 \mathrm{t} / \mathrm{ha}$ com o CMS 649. É importante ressaltar que no estudo citado o consórcio foi realizado na entrelinha, sendo utilizada densidade maior de plantas, o que contribuiu para obtenção de rendimentos mais elevados. Aumento no cultivo consorciado foi constatado por REZENDE (1995) que observou acréscimos de $6,25 \%$ no rendimento de matéria seca do milho e soja consorciados em relação ao monocultivo desta gramínea.

Para o rendimento de massa verde e matéria seca total, a interação corte $\mathrm{x}$ sorgo, depois de desdobrada, indicou diferenças significativas entre os cortes apenas para o híbrido AG 2002 no rendimento de massa verde total acrescido dos híbridos AG 2006 e BR 601 para matéria seca total, quando se compara o efeito de corte dentro de cada híbrido de sorgo. Por outro lado, estudando o efeito dos híbridos de sorgo dentro de cada sistema de corte, verifica-se uma perfor-

penho, tanto no monocultivo quanto no consórcio, possibilitou à soja maior desempenho provocando aumentos em todas combinações consorciadas e algumas até significativas como ocorreu com a combinação Doko RC x CMSXS 756 no sistema de um e dois cortes.

No caso de matéria seca total, uma vez que ocorreu efeito significativo do monocultivo sobre o consórcio, o aparecimento de combinações consorciadas de valor superior ao monocultivo foram mais restritas. Esse fato foi observado com as combinações UFV-17 x AG 2002, Doko RC x AG 2006 e CAC-1, UFV-17 x BR 601. Com o híbrido mance superior com o híbrido AG 2002 apenas no sistema de um corte, com um rendimento de massa verde e matéria seca total de $53,031 \mathrm{~kg} / \mathrm{ha}$ e $16.860 \mathrm{~kg} / \mathrm{ha}$, respectivamente. No sistema de dois cortes, esses resultados não foram observados, tendo os híbridos AG 2002, AG 2006 e BR 601 apresentado rendimento semelhantes (Tabelas 3 e 4). Em ambos os sistemas de corte, o híbrido CMSXS apresentou rendimento inferior aos demais.

Com relação ao monocultivo, a performance dos híbridos foi a mesma do consórcio, com destaque especial para o híbrido AG 2002 que mostrou um rendimento de massa verde de $56.500 \mathrm{~kg} / \mathrm{ha}$, 
seguido dos híbridos BR 601 e AG 2006, o mesmo se verificando em relação à matéria seca. Resultados semelhantes foram observados por outros pesquisadores (PEREIRA et al., 1993 e COSTA \& AZEVEDO, 1996). Os resultados referentes à cultura do sorgo obtidos neste trabalho evidenciam que não há necessidade de se conduzir um programa específico de melhoramento para os híbridos utilizados visando à produção de forragem no sistema consorciado pois, como já discutido anteriormente, houve uma estabilidade na performance dos mesmos, em ambos os sistemas de cultivo, pois o híbrido de maior rendimento no monocultivo foi o mesmo do consórcio (Tabelas 3 e 4$)$.

Os baixos rendimentos observados para o híbrido CMSXS 756 em condição de monocultivo 5708 e $3176 \mathrm{~kg} / \mathrm{ha}$ para massa verde e matéria seca respectivamente, devem-se a sua má adaptação na região em decorrência de menor porte, precocidade e alta exigência em fertilidade. Conforme pode-se observar, em média foi o híbrido que apresentou maior teor de matéria seca, 55,64\%, mas de baixo rendimento forrageiro.

\section{Rendimento de Proteína Bru-} ta Total

Essa característica foi influenciada significativamente pelas fontes de variação corte, híbridos de sorgo, entre monocultivo e pelo contraste consórcio versus monocultivo (Tabela 2).

Ao contrário do que ocorreu com o rendimento de massa verde e matéria seca total, para a proteína bruta total a contribuição do consórcio é relevante. Neste sistema, em média, o consórcio superou o monocultivo em $61,43 \%$ (427kg/ha). Dentro do sistema consorciado, levando em consideração a média dos dois sistemas, constata-se superioridade do sistema de dois cortes de $13,92 \%(146 \mathrm{~kg} / \mathrm{ha})$ em relação ao primeiro sistema, devido, em grande parte, ao maior rendi- mento da cultivar Doko RC que apresentou a maior rebrota dentre as cultivares de soja, contribuindo, dessa forma, para o maior rendimento de proteína bruta no sistema de dois cortes (Tabela 5). Destacase, mais uma vez, a importância do consórcio da leguminosa na adição de proteína à forragem, melhorando seu valor nutritivo, fato esse constatado por vários autores (EVANGELISTA, 1986; OLIVEIRA, 1989; LIMA, 1992 e SOOD \& SHARMA, 1992).

No sistema de um corte, todas as combinações de consórcio superaram o monocultivo

Tabela 5 - Resultados médios de proteína bruta de sorgo e soja $(\mathrm{kg} / \mathrm{ha})$ obtidos no ensaio de avaliação de cultivares de sorgo e soja em consórcio e monocultivo visando à produção de forragem, UFLA Lavras (MG),1996/97.

\begin{tabular}{|c|c|c|c|}
\hline TRATAMENTO & SIST. DE UM CORTE & SIST. DE DOIS CORTES & MÉDIA \\
\hline CAC-1 x AG 2002 & $938^{\mathrm{NS}}$ & $1.301^{\mathrm{NS}}$ & 1.120 \\
\hline CAC-1 x AG 2006 & $1.261 *$ & $1.239^{\mathrm{NS}}$ & 1.250 \\
\hline CAC-1 x BR 601 & $1.136^{* *}$ & $1.099 *$ & 1.118 \\
\hline CAC-1 x CMSXS 756 & $808 * *$ & $822 * *$ & 815 \\
\hline Doko RC x AG 2002 & $1.131^{\mathrm{NS}}$ & $1.315^{\mathrm{NS}}$ & 1.223 \\
\hline Doko RC x AG 2006 & $1.069^{\mathrm{NS}}$ & $1.538 * *$ & 1.303 \\
\hline Doko RC x BR 601 & $1.080 *$ & $1.480 * *$ & 1.279 \\
\hline Doko RC x CMSXS 756 & $888 * *$ & $1.180 * *$ & 1.034 \\
\hline UFV-16 x AG 2002 & $1.392 *$ & $1.249^{\mathrm{NS}}$ & 1.320 \\
\hline UFV-16 x AG 2006 & $1.149^{\mathrm{NS}}$ & $1.152^{\mathrm{NS}}$ & 1.150 \\
\hline UFV-16 x BR 601 & $947^{\mathrm{NS}}$ & $1.426^{* *}$ & 1.187 \\
\hline UFV-16 x CMSXS 756 & $824 * *$ & $753 * *$ & 789 \\
\hline UFV-17 x AG 2002 & $1.277^{\mathrm{NS}}$ & $1.184^{\mathrm{NS}}$ & 1.230 \\
\hline UFV-17 x AG 2006 & $1.042^{\mathrm{NS}}$ & $1.369 * *$ & 1.205 \\
\hline UFV-17 x BR 601 & $946^{\mathrm{NS}}$ & $1.244^{* *}$ & 1.095 \\
\hline UFV-17 x CMSXS 756 & $888 * *$ & $773 * *$ & 831 \\
\hline CAC-1 x SORGO & 1.036 & 1.115 & 1.076 \\
\hline Doko RC x SORGO & 1.042 & 1.378 & 1.210 \\
\hline UFV-16 x SORGO & 1.078 & 1.145 & 1.112 \\
\hline UFV-17 x SORGO & 1.038 & 1.143 & 1.091 \\
\hline AG $2002 \times$ SOJA & 1.185 & 1.262 & $1.224 \mathrm{a}$ \\
\hline AG $2006 \times$ SOJA & 1.130 & 1.325 & $1.228 \mathrm{a}$ \\
\hline BR 601 x SOJA & 1.027 & 1.313 & $1.170 \mathrm{a}$ \\
\hline CMSXS 756 x SOJA & 852 & 882 & $867 \mathrm{~b}$ \\
\hline MÉDIA & $1.049 \quad \mathrm{~B}^{2}$ & $1.195 \mathrm{~A}$ & 1122 \\
\hline MONOCULTIVO & & & \\
\hline AG 2002 & $1.021 \mathrm{a}^{1}$ & & \\
\hline AG 2006 & $885 \mathrm{ab}$ & & \\
\hline BR 601 & $649 \quad b$ & & \\
\hline CMSXS 756 & $227 \quad \mathrm{c}$ & & \\
\hline MÉDIA & 695 & & \\
\hline
\end{tabular}

1. Médias seguidas pela mesma letra minúscula na coluna não diferem entre si pelo teste de Duncan a $5 \%$ de probabilidade.

2. Médias seguidas pela mesma letra maiúscula na linha não diferem entre si pelo teste de Duncan a $5 \%$ de probabilidade.

** Significativo em nível de $1 \%$; * Significativo em nível de $5 \%$; ${ }^{\text {NS }}$ Não significativo. 
dos respectivos híbridos de sorgo, à exceção da combinação AG 2002 x CAC-1 que no sistema de um corte apresentou rendimento inferior $(938 \mathrm{~kg} / \mathrm{ha})$, porém não significativo em relação ao monocultivo desse híbrido $(1.021 \mathrm{~kg} / \mathrm{ha})$. Nesse sistema, os maiores rendimentos significativos foram verificados com as combinações UFV-16 x AG 2002 $(1.392 \mathrm{~kg} / \mathrm{ha})$ e CAC-1 x AG $2006(1.261 \mathrm{~kg} / \mathrm{ha})$ que superaram o monocultivo dos respectivos híbridos em $36,33 \%$ (371kg/ha) e 42,48\% (376kg/ha).

No sistema de dois cortes, todas combinaç̃es de consórcio superaram o monocultivo dos híbridos de sorgo. Aumentos significativos somente não foram obtidos com o híbrido AG 2002 e com a utilização do híbrido AG 2006 x UFV-16. Os maiores rendimentos foram obtidos com as combinações Doko RC com os híbridos AG 2006 (1.538kg/ha) e BR 601 (1.480kg/ha), superando os respectivos monocultivos em $73,79 \%(653 \mathrm{~kg} / \mathrm{ha})$ e $128,04 \%$ $(831 \mathrm{~kg} / \mathrm{ha})$ e também em $50,64 \%(517 \mathrm{~kg} / \mathrm{ha})$ e $44,96 \%$ (459kg/ha), em relação ao monocultivo do AG 2002 de maior rendimento (Tabela 5).

Em monocultivo, o híbrido AG 2002 destaca-se novamente com um rendimento de $1.021 \mathrm{~kg} / \mathrm{ha}$, seguido pelo AG 2006 (885kg/ha), BR $601(649 \mathrm{~kg} / \mathrm{ha})$ que não diferiram entre si e pelo CMSXS 756 (227kg/ha). Pereira et al. (1993) obtiveram rendimentos de $1,08 \mathrm{t} / \mathrm{ha}$ de proteína bruta para o híbrido AG 2002 e 1,34t/ha para o AG 2004, sendo superiores aos rendimentos obtidos neste ensaio.

\section{CONCLUSÕES}

O sistema de um corte é superior ao de dois cortes em termos de rendimentos de massa verde e matéria seca. No caso da proteína bruta total, a superioridade é observada em favor do sistema de dois cortes.

A utilização do consórcio proporcionou maior rendimento de proteína bruta total quando comparado ao monocultivo. As combinações UFV16 x AG 2002 e CAC-1 x AG 2006 são as de maior destaque para o sistema de um corte. No sistema de dois cortes, sobressairam-se Doko RC x AG 2006 e DOKO RC x BR 601.

Em condição de monocultivo e consórcio, o híbrido de sorgo que proporciona maior rendimento de massa verde, matéria seca e proteína bruta total é o AG 2002.

\section{REFERÊNCIAS BIBLIOGRÁFICAS}

CARVALHO, A.J.C.de. Comportamento de cultivares e linhagens de soja (Glycine max (L.) Merrill) em consórcio com milho (Zea mays L.) de ciclos e portes diferentes. La- vras, MG, 1993. 70p. Dissertação (Mestrado em Fitotecnia)Curso de Pós-graduação em Fitotecnia, Escola Superior de Agricultura de Lavras, 1993.

COMISSÃO DE FERTILIDADE DO SOLO DO ESTADO DE MINAS GERAIS. Recomendações para o uso de corretivos e fertilizantes em Minas Gerais. $4^{\mathrm{a}}$ aproximação. Lavras : EPAMIG, 1989. 159p.

COSTA, N.de L., AZEVEDO, D.M.P.de. Produção e composição química de cultivares de sorgo forrageiro. In CONGRESSO NACIONAL DE MILHO E SORGO, 21, Londrina, 1996. Resumos... Londrina : IAPAR, 1996. p. 216.

EVANGELISTA, A.R. Consórcio milho-soja e sorgo-soja: rendimento forrageiro, qualidade e valor nutritivo das silagens. Viçosa, MG, 1986. 77p. Tese (Doutorado em Zootecnia)-Curso de Pós-graduação em Zootecnia, Universidade Federal de Viçosa, 1986.

FARIA, V.P.de. Técnicos de produção de silagens, Piracicaba, SP, 1986. In: SIMPOSIO SOBRE MANEJO DE PASTAGENS 8, 1986, Piracicaba, SP. Anais... Piracicaba : FEALQ, 1986. p 119-144.

FEHR, W.R., CAVINESS, C.E. Stage of soybean development. Ames : Lowa State University, 1977. 12p. (Special Report, 80)

LIMA, J.A.de. Qualidade e valor nutritivo da silagem mista de capim-elefante (Pennisetum purpureum Schum) e soja (Glycine max L. Merrill), com e sem adição de farelo de trigo. Lavras, MG, 1992. 69p. Dissertação (Mestrado em Zootecnia) - Curso de Pós-graduação em Zootecnia, Escola Superior de Agricultura de Lavras, 1992.

MALAVOlTA, E, VITTI, G.C., OLIVEIRA, S.A Avaliação do estado nutricional das plantas: princípios e aplicações. $\mathrm{Pi}$ racicaba : Potafos, 1989. 201p.

OLIVIERA, J.M.de. Rendimento, qualidade da forragem e valor nutritivo das silagens de sorgo (Sorghum bicolor $(\mathbf{L}$. Moench), forrageiro e granífero, consorciado com soja (Glycine max (L.) Merrill). Viçosa, MG, 1989. 57p. Tese (Doutorado em Zootecnia) - Curso de Pós-graduação em Zootecnia, Universidade Federal de Viçosa, 1989.

PEREIRA, O.G., OBEID, J.A., GOMIDE, J.A., et al. Produtividade de uma variedade de milho (Zea mays L.) e de três variedades de sorgo (Sorghum bicolor (L.) Moench) e o valor nutritivo de suas silagens. Revista Ceres, Viçosa, v.22, n.1, p.31-38. jan./fev. 1993.

REZENDE, P.M. de. Capacidade competitiva de cultivares de milho e soja consorciados em função da produção de grãos e forragem. Lavras, MG, 1995. 154p. Tese (Doutorado em Fitotecnia) - Curso de Pós-graduação em Fitotecnia, Escola Superior de Agricultura de Lavras, 1995.

REZENDE, P.M. de, ANDRADE, M.J.B. de, ANDRADE, L.A. de B. Consórcio soja-milho. II. Seleção de materiais genéticos de soja para consórcio com milho. Ciência e Prática, Lavras, v.16, n.3, p.333-341, jul./set.1992.

SOOD, B.R., SHARMA, V.K. Effect of nitrogen level on the yield and quality of forage sorghum (Sorghum bicolor) intercropped with legumes. Indian Journal of Agronomy, New Delhi, v.37, n.4, p.642-644, Dec. 1992. 